\title{
Recursos Didáticos nas Aritméticas da Série Ordem e Progresso e da Série Concórdia
}

\section{Didactic Resources in the Arithmetic of the Order and Progress Series and of the Concord Series}

\author{
Malcus Cassiano Kuhn ${ }^{\text {a,b }}$; Arno Bayer ${ }^{b}$ \\ a Instituto Federal de Educação, Ciência e Tecnologia Sul-rio-grandense, Lajeado, Brasil - malcuskuhn@ifsul.edu.br \\ b Universidade Luterana do Brasil, Canoas, Brasil - bayer@ulbra.br
}

\begin{abstract}
Palavras-chave: Recursos didáticos. Série Ordem e Progresso. Série Concórdia. Ensino da matemática. Escolas paroquiais luteranas gaúchas.
\end{abstract}

Resumo: O artigo tem por objetivo discutir recursos didáticos encontrados nas aritméticas da série Ordem e Progresso e da série Concórdia, baseando-se na história cultural. Essas aritméticas foram editadas pela Igreja Evangélica Luterana do Brasil para suas escolas, no Rio Grande do Sul, na primeira metade do século XX. Na análise de seis aritméticas se observaram: ilustrações para construção intuitiva do conceito de número e estudo das frações, unidades do sistema de medidas, sistema monetário e operações comerciais; propostas para utilização de materiais concretos no estudo do sistema decimal, quatro operações com números naturais, frações, números decimais e unidades do sistema de medidas. Os autores usaram a estratégia de empregar recursos didáticos que faziam parte de diferentes contextos da realidade dos alunos das escolas paroquiais luteranas gaúchas do século passado, com a expectativa de que os mesmos se apropriassem dos conhecimentos matemáticos.

\begin{abstract}
Keywords:
Didactic resources, Order and Progress Series. Concordia Series. Mathematics teaching. Gaucho lutheran parochial schools.
\end{abstract}

\begin{abstract}
The article aims to discuss didactic resources observed in the arithmetic of the Order and Progress series and of the Concordia series, basing on the cultural history. Those arithmetic were edited by the Evangelical Lutheran Church of Brazil for their schools in Rio Grande do Sul, in the first half of the 20th century. In the analysis of six arithmetic were observed: illustrations for intuitive construction of the concept of number and study of the fractions, units of the measures system, monetary system and commercial operations; proposals for utilization of concrete materials in the study of the decimal system, four operations with natural numbers, fractions, decimals numbers and units of the measures system. The authors used the strategy of employing didactic resources that were part of different contexts of the reality of students of the gaucho Lutheran parochial schools of the past century, with the expectation that the same appropriated of the mathematical knowledges.
\end{abstract}




\section{Introdução}

$\mathrm{O}$ artigo discute os recursos didáticos encontrados nas aritméticas da série Ordem e Progresso e da série Concórdia, editadas pela Igreja Luterana para suas escolas no Rio Grande do Sul - RS, na primeira metade do século XX. Trata-se de um recorte da tese sobre $O$ ensino da Matemática nas Escolas Evangélicas Luteranas do Rio Grande do Sul durante a primeira metade do século $\mathrm{XX}$, complementado por pesquisas realizadas durante o estágio Pósdoutoral, junto ao Programa de Pós-Graduação em Ensino de Ciências e Matemática PPGECIM - da Universidade Luterana do Brasil - ULBRA - Canoas/RS.

O movimento migratório no RS tem sido objeto de investigações. No âmbito da História da Educação no RS, os trabalhos de Kreutz (1991, 1994, 2008), Rambo (1994, 1996), Lemke (2001), Arendt (2005) e Weiduschadt (2007, 2012) são destaques. Na História da Educação Matemática no RS, destacam-se as pesquisas de Mauro (2005), Kreutz e Arendt (2007), Wanderer (2007), Silva (2014, 2015) e Kuhn (2015).

Como a temática investigada se insere na História da Educação Matemática no RS, busca-se na história cultural o suporte para discussão. Segundo Chartier (1990), uma questão desafiadora para a história cultural é o uso que as pessoas fazem dos objetos que lhes são distribuídos ou dos modelos que lhes são impostos, uma vez que há sempre uma prática diferenciada na apropriação dos objetos colocados em circulação.

Chervel (1990) considera importante o estudo histórico da cultura escolar para a compreensão dos elementos que participam da produção/elaboração/constituição dos saberes escolares e, em particular, da matemática escolar e sua história. Julia (2001) define a cultura escolar como um conjunto de normas que estabelecem conhecimentos a ensinar e condutas a inspirar, e um conjunto de práticas que permitem a transmissão desses conhecimentos e a incorporação desses comportamentos. De acordo com Valente (2007), pensar os saberes escolares como elementos da cultura escolar, realizar o estudo histórico da matemática escolar, exige que se devam considerar os produtos dessa cultura no ensino da matemática, que deixaram traços que permitem o seu estudo, como as aritméticas da série Ordem e Progresso e da série Concórdia, principais fontes documentais desta investigação.

Precedendo a discussão dos recursos didáticos observados nas aritméticas da série Ordem e Progresso e série Concórdia, apresenta-se uma breve caracterização das escolas paroquiais luteranas gaúchas do século XX. 


\section{As escolas paroquiais luteranas gaúchas do século $\mathrm{XX}$}

Em 1900, o Sínodo Evangélico Luterano Alemão de Missouri ${ }^{1}$, atualmente Igreja Evangélica Luterana do Brasil - IELB, iniciou sua missão nas colônias alemãs do RS, fundando congregações religiosas e escolas paroquiais. "A escola paroquial se revelou como uma grande benção para o bem e o desenvolvimento da Igreja Luterana. As congregações que mantinham escolas paroquiais, geralmente eram as melhores congregações" (WARTH, 1979, p. 195).

De acordo com Kuhn (2015), as escolas paroquiais luteranas estavam inseridas num projeto missionário e comunitário que buscava ensinar a língua materna, a matemática, valores culturais, sociais e, principalmente, religiosos. Tinham uma responsabilidade para com a comunidade no sentido de, junto e com ela, promover o crescimento e o desenvolvimento pessoal de todos que a compõe, focando a cidadania. Se a escola formasse o ser humano com postura ética e moral exemplar, este poderia promover transformações sólidas em seu contexto social e seria um verdadeiro colaborador na seara de Deus e para o governo do mundo. As escolas paroquiais luteranas gaúchas foram assim caracterizadas por Weiduschadt (2007):

As escolas eram organizadas de forma multisseriada. As turmas eram compostas de 20 a 40 alunos. Na maioria das vezes, o pastor da comunidade era, ao mesmo tempo, professor. A comunidade sustentava a estrutura física e mantinham o professor da escola. O prédio era muitas vezes o mesmo local do templo. A ligação entre a escola e a igreja era importante, porque logo no início da formação das comunidades o ensino doutrinário e pedagógico era ressaltado e sua suplementação implicava questões econômicas e culturais para a implementação. O projeto escolar dentro da comunidade religiosa era marcante, a orientação e a obrigação de os pais enviarem os filhos à escola eram quase obrigatórias, com sanções econômicas e morais, caso não concordassem (WEIDUSCHADT, 2007, p. 166-168).

O Sínodo de Missouri também tinha uma preocupação acentuada em relação aos recursos didáticos usados nas escolas paroquiais, pois este material era escasso e a dificuldade era grande em manter um ensino planificado e organizado. De acordo com Weiduschadt (2007, p. 41), “os livros usados nas escolas paroquiais e utilizados pelos alunos foram produzidos pelas instituições religiosas com objetivo de formar e moldar as condutas e as práticas ao fazer a escolarização das comunidades". Assim, por meio dos livros didáticos, como as aritméticas da série Ordem e Progresso e série Concórdia, as escolas paroquiais luteranas gaúchas conseguiram desenvolver uma educação integral cristã em todas as disciplinas. Nessas escolas, conforme Lemke (2001, p. 80), “o ensino da Palavra de Deus,

\footnotetext{
${ }^{1}$ Em 1847, um grupo de imigrantes luteranos alemães da Saxônia fundou no estado de Missouri (EUA), o Sínodo Evangélico Luterano Alemão de Missouri, Ohio e Outros Estados, atualmente Igreja Luterana - Sínodo de Missouri (WARTH, 1979).
} 
através da Bíblia, ficava em primeiro lugar, as demais disciplinas não eram menosprezadas, mas complementavam a educação para servir no mundo".

\section{O ensino da matemática nas escolas paroquiais luteranas gaúchas do século $\mathrm{XX}$}

Conforme Kuhn (2015), o ensino da matemática, nos primeiros anos de escolarização nas escolas paroquiais luteranas gaúchas do século passado, priorizava os números naturais, os sistemas de medidas, as frações ordinárias e decimais, complementando com a matemática comercial e financeira e a geometria. $\mathrm{O}$ ensino da matemática deveria acontecer de forma prática e articulada com as necessidades dos futuros agricultores, observando-se a ideologia luterana.

De acordo com Kreutz (1994), a prioridade eram as operações básicas que pudessem ser feitas mentalmente, nas circunstâncias concretas da vida agrária, seja na forma, como no conteúdo. Por isso, dava-se ênfase aos Kopfrechnungen (cálculos feitos mentalmente), já que na vida agrícola a pessoa teria que calcular, com frequência, sem ter o papel e lápis à mão. $\mathrm{O}$ próprio título de um dos manuais usados nesta disciplina, o Praktische Rechenschule (o ensino prático da matemática), de Otto Büchler, reflete este entendimento. Ressalta-se que até mais ou menos 1932, predominava o ensino tradicional no Brasil. De 1932 até 1960, os alunos sofreram as influências do evolucionismo e do pragmatismo, período denominado de Escola Nova. O movimento ganhou impulso no Brasil, após a divulgação do Manifesto dos Pioneiros da Educação Nova, em 1932. Nesse documento, defendia-se a universalização da escola pública, laica e gratuita. Conforme Nunes (1998), a Escola Nova visava colocar o educando como centro do processo educativo e atender aos desafios da sociedade, de forma crítica e dialogada.

Com relação ao ensino da matemática nas escolas paroquiais missourianas, Lindemann (1888) afirma que:

\footnotetext{
Nas classes iniciais importa que as crianças entendam intuitivamente a ideia dos números e do sistema decimal. Logo, nos primeiros anos de escola será suficiente que as crianças compreendam os números de 1 a 1000 corretamente, saibam ler e escrever os números e executar os cálculos básicos envolvendo as quatro operações. Nos anos seguintes, devem aprender as quatro operações com todos os números e também os números decimais. Mais adiante, aprendem as frações comuns, unidades de medida, cálculos com preços e percentagem e a solução de tarefas geométricas simples. O treino e memorização de tabelas com unidades de medida, de pesos e moedas devem ser realizadas mais no final da escolarização (LINDEMANN, 1888, p. 51, tradução nossa).
} 
As ideias de Lindemann refletem o uso do método de ensino intuitivo ${ }^{2}$, o qual também foi empregado nas escolas paroquiais luteranas gaúchas do século XX pelos pastores/professores paroquiais vindos dos Estados Unidos e por aqueles formados, posteriormente, no Seminário Concórdia ${ }^{3}$ de Porto Alegre. Em seus princípios metodológicos, o autor aponta para a construção do conceito de número de forma intuitiva, seguida de exercícios para o desenvolvimento de habilidades de cálculo escrito e mental de acordo com o nível dos alunos, e por fim, a aplicação prática do conhecimento matemático formal:

Primeiro trabalhar o conceito de número, seguido do exercício (treino) e depois da aplicação prática. A concepção ou ideia correta de número só pode ser obtida por meio da intuição, sendo esta fundamental no início do ensino da aritmética. Tendo claro o conceito de número, os alunos devem fazer muitos e variados exercícios. Deve se usar o ábaco e outros materiais concretos, como por exemplo: pedaços de madeira, dados, esferas, botões, grãos de feijão, janelas da sala, as próprias crianças, etc.. A utilização de vários recursos visuais é necessária para que as crianças não construam a ideia de número somente de forma abstrata. No ensino de frações também se deve usar recursos visuais para de forma prática ilustrar as diversas partes da unidade e juntá-las novamente formando o inteiro. Para isto, servem pedaços de madeira, placas, etc., que podem ser desmontados e montados novamente para se desenvolver as ideias de metade, um quarto, um sexto, etc.. Sempre que possível, as tarefas devem levar em conta a vida prática. A criança conhece as moedas do nosso país, as unidades de medida e pesos, necessita realizar cálculos de preços, calcular o lucro e a perda, etc. (LINDEMANN, 1888, p. 188189, tradução nossa).

Destaca-se que os primeiros trinta anos de existência das escolas paroquiais luteranas no estado gaúcho foram marcados pela carência de materiais didáticos e progressiva adoção dos quatro manuais de Büchler, tanto em alemão quanto em português, para as aulas de matemática. No periódico Unsere Schule (ago. 1933, p. 6, tradução nossa), afirma-se que "os livros de aritmética de Büchler (editora Rotermund) ${ }^{5}$ são usados na maioria das nossas escolas e que a mesma editora lançou recentemente um novo manual: meu livro de contas, por W. Nast e L. Tochtrop". Porém, na mesma edição, esse manual é analisado criticamente, apontando-se a necessidade de uma edição com princípios morais e educacionais luteranos, com uso de princípios pedagógicos modernos e adaptada às condições nacionais, pois o processo de nacionalização do ensino estava em curso.

\footnotetext{
${ }^{2}$ Método de ensino que surgiu na Alemanha no final do século XVIII e divulgado pelos discípulos de Pestalozzi no decorrer do século XIX, na Europa e nos Estados Unidos. No Brasil, fez parte das propostas de reformulação da instrução pública no final do Império, sendo Rui Barbosa responsável por sistematizar os princípios do método intuitivo em seus pareceres e por traduzir o manual, Lições de Coisas, de Calkins. No método intuitivo, segundo Valdemarin (2004), a escola deveria ensinar coisas vinculadas à vida, utilizar os objetos como suporte didático e os sentidos para produção de ideias, iniciando do concreto e ascendendo à abstração. Os sentidos deveriam ser educados para obter o conhecimento, passando da intuição dos sentidos para a intuição intelectual.

${ }^{3}$ Instituto pedagógico-teológico que atuou na formação de pastores e de professores paroquiais para IELB.

${ }^{4} \mathrm{Na}$ década de 1930, a IELB começou a publicar um periódico pedagógico dirigido às escolas paroquiais, chamado Unsere Schule (Nossa Escola).

5 A editora Rotermund, de São Leopoldo, editava e publicava o material didático relacionado ao Sínodo RioGrandense (Igreja Evangélica de Confissão Luterana no Brasil - IECLB).
} 
Por isso, o Sínodo de Missouri começou a produzir os próprios livros de aritmética na década de 1930. A Casa Publicadora Concórdia ${ }^{6}$ de Porto Alegre editou e publicou o material didático específico para as escolas paroquiais luteranas. Para as aulas de matemática, foram publicadas duas séries: a série Ordem e Progresso, lançada na década de 1930, pela divulgação feita no periódico Unsere Schule, e a série Concórdia, lançada na década de 1940.

A série Ordem e Progresso e a série Concórdia contém três aritméticas voltadas para o ensino da matemática nos primeiros anos de escolarização. No Instituto Histórico da IELB, em Porto Alegre, localizaram-se a Primeira e a Terceira Arithmetica da série Ordem e Progresso, além de uma edição da Primeira Aritmética, duas edições da Segunda Aritmética e uma edição da Terceira Aritmética da série Concórdia. Ainda não foi localizada a Segunda Aritmética da série Ordem e Progresso.

A investigação dos recursos didáticos observados nas aritméticas da série Ordem e Progresso e da série Concórdia, brevemente apresentadas no Quadro 1, fundamenta-se no referencial teórico-metodológico da história cultural.

Quadro 1 - Aritméticas analisadas

\begin{tabular}{|c|c|c|c|c|}
\hline Obra & Série & Data & Autor & Páginas \\
\hline Primeira Aritmética & $\begin{array}{c}\text { Ordem e } \\
\text { Progresso }\end{array}$ & {$[193-]$} & Prof. Frederico Strelow ${ }^{7}$ & 64 \\
\hline Terceira Arithmetica & $\begin{array}{c}\text { Ordem e } \\
\text { Progresso }\end{array}$ & {$[193-]$} & Sem autoria declarada & 143 \\
\hline Primeira Aritmética & Concórdia & {$[194-]$} & Otto A. Goerl $^{8}$ & 68 \\
\hline Segunda Aritmética & Concórdia & {$[194-]$} & Otto A. Goerl & 84 \\
\hline Segunda Aritmética & Concórdia & 1948 & Sem autoria declarada & 96 \\
\hline Terceira Aritmética & Concórdia & 1949 & Sem autoria declarada & 143 \\
\hline
\end{tabular}

Fonte: Série Ordem e Progresso e série Concórdia.

A partir do Quadro 1 se verifica que somente três aritméticas possuem autoria declarada, porém, acredita-se que os autores das demais obras também tenham sido professores das escolas paroquiais luteranas, pois o periódico Unsere Schule se refere à edição de livros de aritmética da seguinte maneira: “o Sínodo decidiu que será editado um trabalho completo de aritmética. Os professores Frederico Strelow, Albert Brückmann e Max Öhlwein foram contratados para realizar o trabalho" (UNSERE SCHULE, mar./abr. 1934, p. 14, tradução nossa). Observa-se ainda que o número de páginas de cada livro aumenta conforme o

\footnotetext{
${ }^{6}$ Fundada em 1923, fazia a edição de livros e de periódicos relacionados à literatura religiosa e escolar da IELB. Foi a primeira e a única editora da IELB, existente até os dias atuais. Antes de sua fundação, os livros e os periódicos eram impressos pela Concordia Publishing House, nos Estados Unidos, e enviados ao Brasil.

${ }^{7}$ Frederico Strelow (1888-1946) se formou na primeira turma de professores no Seminário Concórdia, em abril de 1912. Foi professor paroquial, redator do periódico pedagógico Unsere Schule e autor da Primeira Aritmética da série Ordem e Progresso.

${ }^{8}$ O gaúcho Otto Adolpho Goerl (1905-1998) se formou no Seminário Concórdia, em 1925, e foi ordenado pastor em 1926. Além de pastor, foi professor paroquial e, posteriormente, professor e diretor do Seminário Concórdia. Autor de livros para o ensino da aritmética e da leitura nas escolas paroquiais luteranas.
} 
nível de escolarização primária e que as duas edições da Terceira Aritmética têm o mesmo número de páginas (143), abordam as mesmas unidades de estudo e exercícios, com a mesma distribuição de páginas para cada conteúdo no livro, havendo apenas variações na ortografia de palavras e na representação de unidades de medida e do sistema monetário. Não se pode informar a quantidade de exemplares publicados de cada edição, pois esta informação não foi encontrada.

\section{Os recursos didáticos nas aritméticas das séries Ordem e Progresso e Concórdia}

A Primeira Aritmética da série Ordem e Progresso enfatiza o estudo da numeração até 100. O estudo dos números de 0 a 100 inicia com a numeração de 0 a 10 , explorando o significado de quantidades até 10 e as operações de adição e subtração. Depois, amplia-se o estudo com os números até 100, envolvendo a escrita em ordem crescente e decrescente dos números e as operações de adição, subtração, multiplicação e divisão. Destaca-se a existência de inúmeras propostas de cálculos orais e por escrito com o algoritmo na horizontal, envolvendo as quatro operações com números naturais até 100. Na introdução dos números até 10 se observa que o autor emprega o método de ensino intuitivo, mas no restante da obra predominam propostas de ensino marcadas pela retórica e memorização, como o exemplo apresentado no Quadro 2:

Quadro 2 - Como se decora as tabuadas de multiplicar

\begin{tabular}{|c|c|c|c|c|}
\hline \multicolumn{5}{|c|}{ Exemplo: A tabuada de 2. } \\
\hline $\begin{array}{c}\text { 1) Pela ordem } \\
\text { crescente }\end{array}$ & $\begin{array}{c}\text { 2) Pela ordem } \\
\text { decrescente }\end{array}$ & $\begin{array}{c}\text { 3) Salteando } \\
\text { crescente }\end{array}$ & $\begin{array}{c}\text { 4) Salteando } \\
\text { decrescente }\end{array}$ & $\begin{array}{c}\text { 5) Salteando } \\
\text { misto }\end{array}$ \\
$1 \times 2=$ & $10 \times 2=$ & $1 \times 2=$ & $10 \times 2=$ & $1 \times 2=$ \\
$2 \times 2=$ & $9 \times 2=$ & $3 \times 2=$ & $8 \times 2=$ & $10 \times 2=$ \\
$3 \times 2=$ & $8 \times 2=$ & $5 \times 2=$ & $6 \times 2=$ & $2 \times 2=$ \\
$4 \times 2=$ & $7 \times 2=$ & $7 \times 2=$ & $4 \times 2=$ & $9 \times 2=$ \\
$5 \times 2=$ & $6 \times 2=$ & $9 \times 2=$ & $2 \times 2=$ & $3 \times 2=$ \\
$6 \times 2=$ & $5 \times 2=$ & $2 \times 2=$ & $9 \times 2=$ & $8 \times 2=$ \\
$7 \times 2=$ & $4 \times 2=$ & $4 \times 2=$ & $7 \times 2=$ & $4 \times 2=$ \\
$8 \times 2=$ & $3 \times 2=$ & $6 \times 2=$ & $5 \times 2=$ & $7 \times 2=$ \\
$9 \times 2=$ & $2 \times 2=$ & $8 \times 2=$ & $3 \times 2=$ & $5 \times 2=$ \\
$10 \times 2=$ & $1 \times 2=$ & $10 \times 2=$ & $1 \times 2=$ & $6 \times 2=$ \\
\hline
\end{tabular}

Fonte: Strelow, [193-], p. 50.

O Quadro 2 ilustra a proposta do autor para se memorizar as tabuadas de multiplicar, exemplificando com a tabuada de 2 e indicando os seguintes passos: $1^{\circ}$ pela ordem crescente, $2^{\circ}$ pela ordem decrescente, $3^{\circ}$ salteando crescente (primeiro os fatores ímpares e depois os fatores pares, em ordem crescente), $4^{\circ}$ salteando decrescente (primeiro os fatores pares e depois os fatores ímpares, em ordem decrescente) e $5^{\circ}$ salteando misto (intercalando ordem crescente e ordem decrescente). Depois, propõe a aplicação deste procedimento com as tabuadas de multiplicar de 3 até 10, oralmente e por escrito. Essa aritmética também apresenta 
uma proposta de estudo para decorar as tabuadas de dividir de 2 até 10, de forma semelhante à proposta para decorar as tabuadas de multiplicar. Ficando subentendida a ideia de que a multiplicação e a divisão são operações inversas.

O estudo da numeração até 10 é feito por uma sistematização que associa quantidades de animais ou objetos à representação simbólica do número, seguida de cálculos que envolvem as operações de adição ou subtração. A Figura 1 apresenta a proposta de estudo para o número 2:

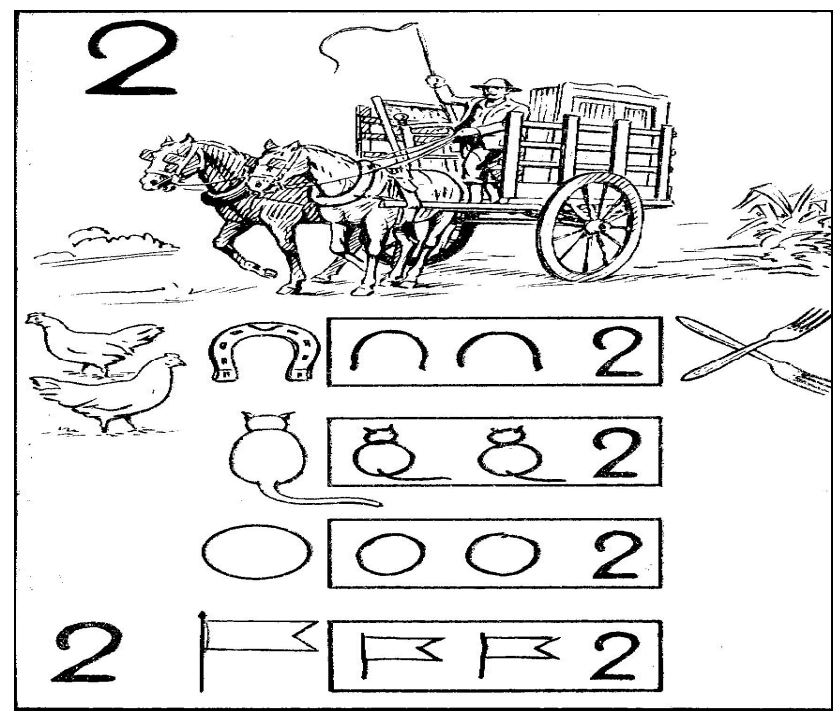

Figura 1 - O número 2

Fonte: Strelow, [193-], p. 2.

O excerto, apresentado na Figura 1, desenvolve a construção do conceito de número de forma intuitiva, associando o número 2 com a representação de 2 animais ou 2 objetos, pertencentes ao contexto social dos alunos das escolas paroquiais luteranas gaúchas. Destacase que, para o estudo dos números até 10, o autor do livro usa a estratégia de relacionar, de forma padronizada, a ideia do número com a quantidade de cavalos puxando uma carroça. $\mathrm{Na}$ Figura 1 são 2 cavalos puxando uma carroça. Para o estudo do zero, o autor usa a representação de uma carroça com a ausência de cavalos (0).

O autor desta aritmética faz poucas referências ao uso de materiais concretos, destacando-se a utilização do quadro negro para realização de exercícios de cálculo e do contador mecânico (ábaco), este ilustrado na Figura 2:

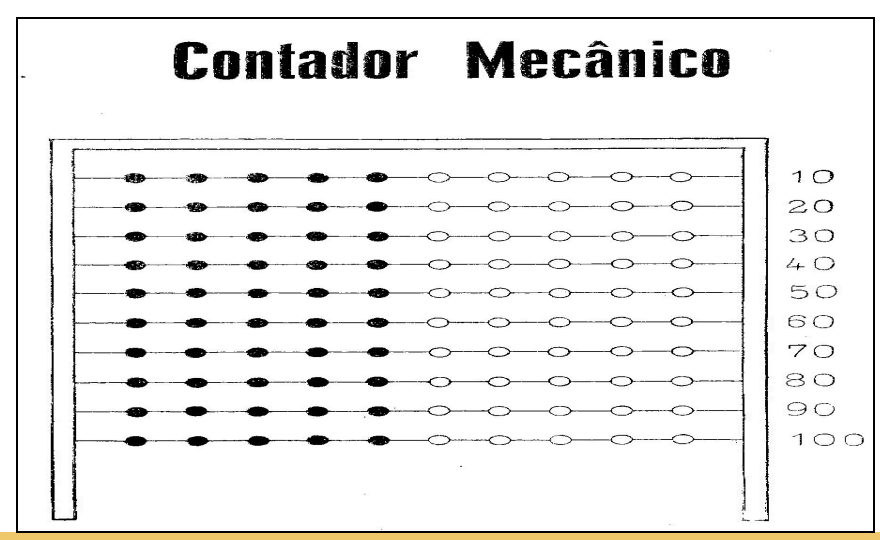


Figura 2 - O contador mecânico

Fonte: Strelow, [193-], p. 38.

A Figura 2 ilustra o contador mecânico ou ábaco como um recurso a ser utilizado em exercícios, propostos na edição da Primeira Aritmética, como a representação e a contagem de números até 100 e as quatro operações elementares com números naturais. Em todas as aritméticas analisadas se observou a proposta de exercícios com a utilização do ábaco. O uso do ábaco nas aulas de matemática das escolas paroquiais é enfatizado nas palavras de Rambo (1994):

Para acelerar e fixar definitivamente a noção de adição e subtração se usava uma moldura na qual estavam fixados dez fios de arame, cada um com dez esferas de madeiras deslocáveis. Qualquer adição ou subtração, dentro da primeira centena, poderia ser feita. Devido a sua importância na alfabetização dos números e cálculos, o citado aparelho, o ábaco, fazia parte obrigatória dos móveis e utensílios de qualquer escola, mesmo as mais pobres e afastadas (RAMBO, 1994, p. 157).

Além do uso do ábaco na construção do conceito de número, especialmente em exercícios de contagem em ordem crescente e decrescente e no desenvolvimento de operações envolvendo os números naturais até 100, o autor da Primeira Aritmética sugere que "as mesmas contas podem ser repetidas com pauzinhos cortados de cabos de vassouras" (STRELOW, [193-], p. 39). De acordo com as orientações didáticas encontradas no periódico pedagógico Unsere Schule, na década de 1930, sugeria-se usar uma multiplicidade de objetos para o desenvolvimento das tarefas matemáticas.

A Primeira Aritmética da série Concórdia está dividida em quatro secções: I Números de 1 a 5, com foco em contar e desenhar, escrever os números, somar e diminuir; II - Números de 1 a 10, com atenção para o significado dos números até 10 e as operações de adição e subtração; III - Números de 1 a 20, ênfase nas operações de adição e subtração; IV Números de 1 a 100, explorando as dezenas, dezenas e unidades, as operações de adição, subtração, multiplicação e divisão, e a pequena tabuada. $\mathrm{O}$ autor desta aritmética dá maior ênfase para o método intuitivo em suas propostas de ensino, mas também traz atividades que enfatizam a tradição pedagógica da memorização (VALENTE; PINHEIRO, 2015).

Nesta aritmética se observa que o estudo da numeração até 10 é proposto de forma intuitiva pelo autor, associando-se quantidades de animais, pessoas ou objetos à representação simbólica do número, seguida de cálculos que envolvem as operações de adição ou subtração até 10. A Figura 3 ilustra a proposta de estudo para o número 7: 


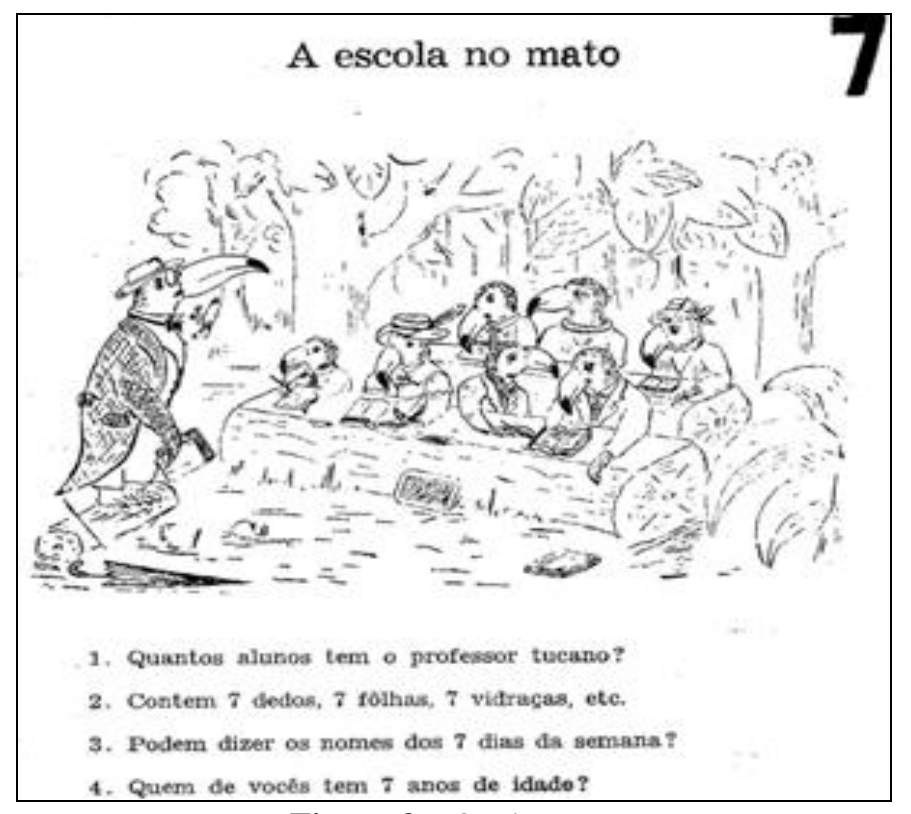

Figura 3 - O número 7

Fonte: Goerl, [194-a], p. 17.

Observa-se que o autor emprega o método de ensino intuitivo para construção do conceito de número, associando o número 7 com a representação de 7 tucanos, propondo a contagem de 7 dedos, 7 folhas e 7 vidraças, além de envolver os nomes dos 7 dias da semana e os alunos que possuem 7 anos de idade. $\mathrm{O}$ autor também apresenta propostas de estudo das quatro operações com número naturais até 100, de forma intuitiva, valendo-se de ilustrações para visualização e desenvolvimento de adições, subtrações, multiplicações e divisões. Empregando o método de ensino intuitivo, o autor esperava que os alunos das escolas paroquiais luteranas gaúchas se apropriassem dos conhecimentos matemáticos.

O autor desta aritmética utiliza a representação da moeda de 10 centavos e faz menção às moedas de 10, 20 e 50 centavos para introduzir a ideia de dezena, conforme o excerto apresentado na Figura 4:

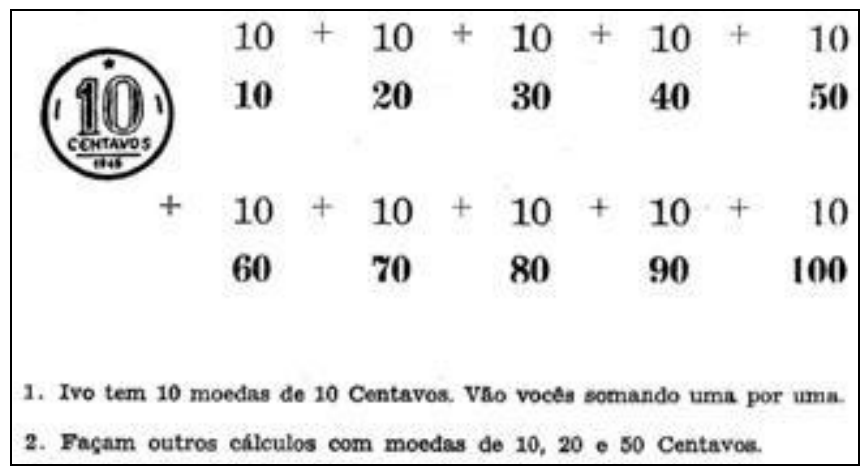

Figura 4 - Dezenas

Fonte: Goerl, [194-a], p. 41.

A partir do fragmento mostrado na Figura 4, observa-se que o autor também busca desenvolver a ideia de dezena de forma intuitiva, usando as moedas do país, conforme orientações pedagógicas de Lindemann (1888). 
A Segunda Aritmética da série Concórdia, do autor Otto A. Goerl, está dividida em três secções: I - Números de 1 a 100 (recapitulação), com as operações de adição, subtração, multiplicação e divisão; II - Números de 1 a 1000, relacionando unidades, dezenas e centenas, bem como as operações de adição, subtração, multiplicação e divisão; III Números até 10000, explorando as classes de milhares, centenas, dezenas e unidades, números pares e ímpares, operações de adição, subtração, multiplicação e divisão. Mesmo que o autor dessa aritmética proponha a resolução de problemas contextualizados com a realidade dos alunos das escolas paroquiais luteranas gaúchas, observam-se várias propostas de ensino para o desenvolvimento de habilidades para o cálculo mental e escrito.

A edição da Segunda Aritmética, editada em 1948, traz como principais unidades de estudo: numeração 1 - 1000; os números até 10000; números além de 10000. Para o estudo dos números até 1000, propõem-se três seções: I - contar, escrever e ler os números: centenas; centenas e dezenas; centenas, dezenas, unidades; II - somar e diminuir: somar e diminuir as unidades; somar e diminuir números de dois algarismos; somar e diminuir números de três algarismos; III - multiplicar e dividir. No estudo dos números até 10000, o livro propõe um roteiro semelhante ao anterior: I - contar, escrever e ler os números; II somar e diminuir; III - multiplicar e dividir. Para o estudo dos números além de 10000, a proposta do livro começa com a leitura e escrita de números, seguida das operações de multiplicação e divisão. Nesta aritmética predominam propostas de ensino para o desenvolvimento de habilidades para o cálculo mental e escrito.

No estudo realizado verificou-se que as duas edições da Segunda Aritmética trazem uma proposta de estudo para as frações ordinárias com foco na compreensão das relações parte-todo (quando um todo é dividido em partes iguais) e quociente (divisão de um número natural por outro diferente de zero). As duas edições exploram estas ideias das frações ordinárias dando ênfase para as frações $\frac{1}{2}, \frac{1}{4}$ e $\frac{1}{3}$, pelo método do ensino intuitivo. Na Figura 5 se mostra como Goerl [194-b] inicia o estudo das frações ordinárias: 


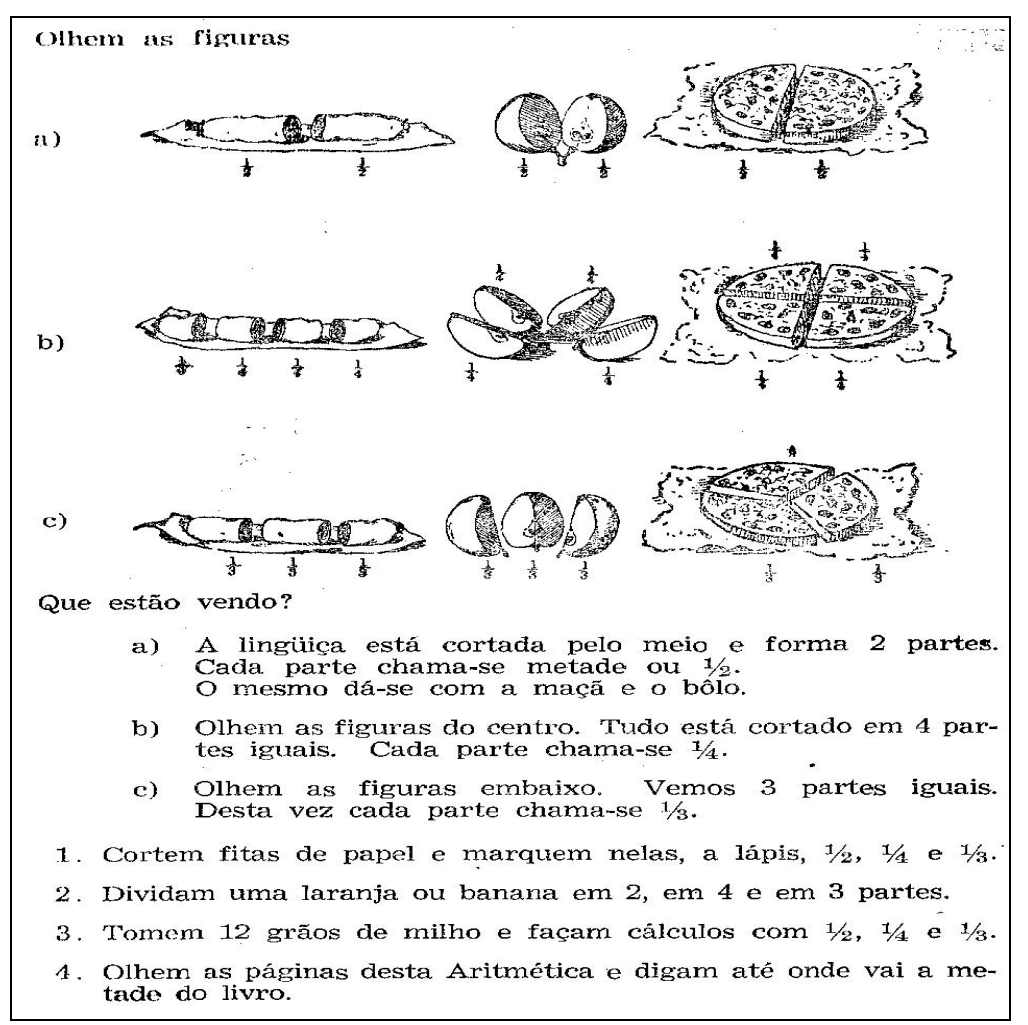

Figura 5 - Sabem o que é $1 / 2,1 / 4,1 / 3$ ?

Fonte: Goerl, [194-b], p. 20.

Conforme a Figura 5, o autor trabalha com a visualização da divisão de uma linguiça, uma maçã e um bolo em duas, quatro e três partes iguais para desenvolver o significado de $\frac{1}{2}$ (metade), $\frac{1}{4}$ (quarta parte) e $\frac{1}{3}$ (terça parte), respectivamente. Em seguida, propõe quatro exercícios com materiais concretos (fitas de papel, laranjas, bananas, grãos de milho e livro) para explorar a ideia de $\frac{1}{2}, \frac{1}{4}$ e $\frac{1}{3}$. Esta proposta pedagógica está de acordo com as orientações didáticas de Lindemann (1888), o qual sugere que no ensino de frações se devem usar recursos visuais para de forma prática ilustrar as diversas partes da unidade e juntá-las novamente formando o inteiro.

A Segunda Aritmética de Goerl também incentiva a consulta ao almanque para realização dos seguintes exercícios: “14) Carlos faltou nas aulas de 5 a 14 de abril. Olhem o almanaque e calculem quantos dias de aulas perdeu. 15) Quantos dias úteis há entre 8 e 19 de maio?" (GOERL, [194-b], p. 22). Para fazer os exercícios 14 e 15 do livro, o autor sugere a consulta ao almanaque. Assim, observando-se o calendário seria possível responder aos exercícios propostos. Na Segunda Aritmética de 1948 e nas edições da Terceira Aritmética também se observaram atividades com o uso do almanaque. Conforme Rockenbach e Flores (2004), os almanaques eram publicados anualmente, com o calendário, dicas de saúde e textos religiosos. Conforme Willems (1980), eles contribuíram para preservação da língua alemã e de uma identidade teuto-brasileira entre os imigrantes alemães no RS. 
Goerl [194-b] coloca os alunos em contato com os números decimais através de uma situação que envolve o envio de correspondências, como descrito no Quadro 3:

Quadro 3 - Enviando cartas pelo correio

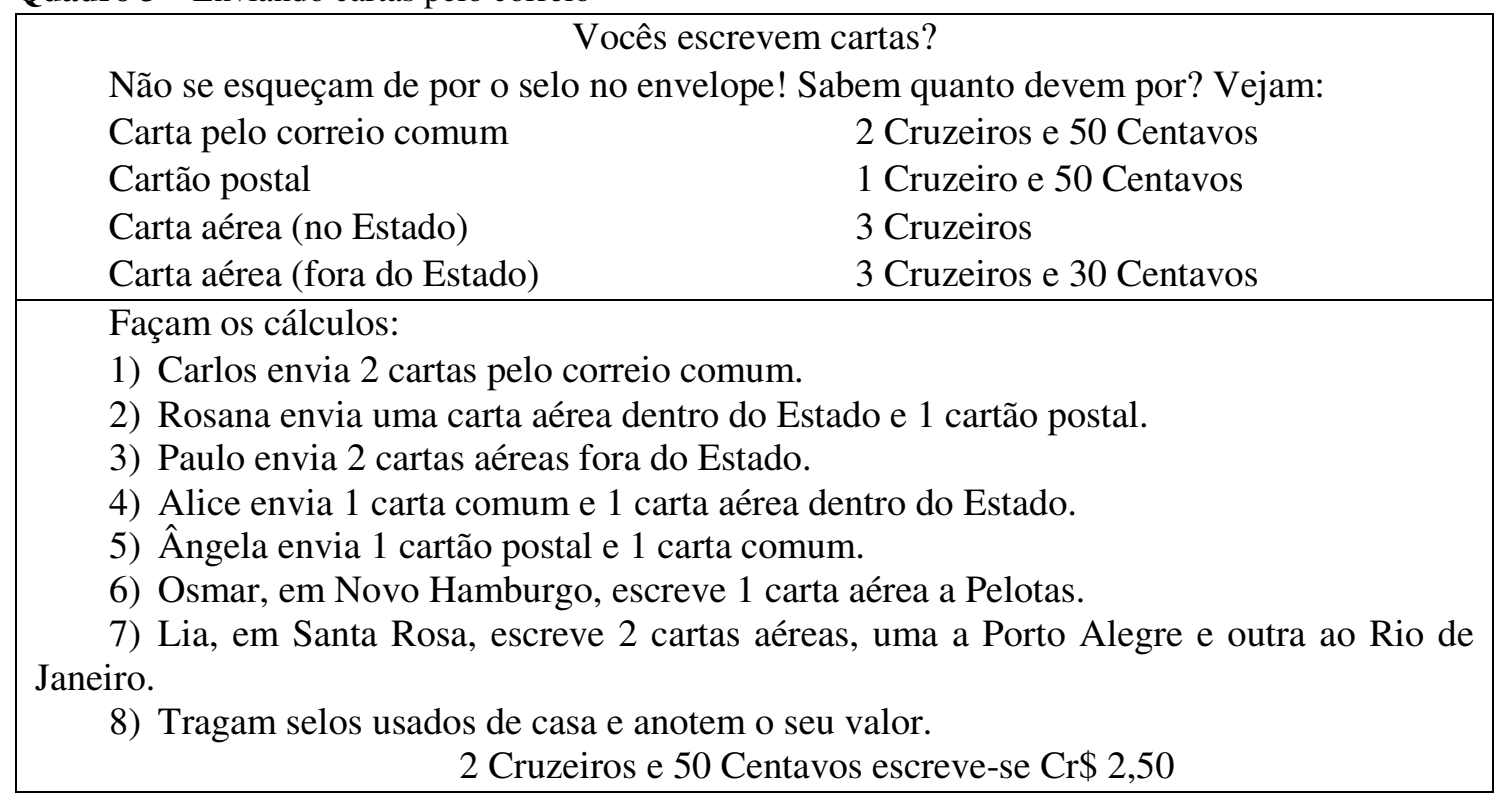

Fonte: Goerl, [194-b], p. 30.

As atividades da Segunda Aritmética, apresentadas no Quadro 3, deveriam ser realizadas a partir dos preços de envio de correspondências, seja envio de carta pelo correio comum, cartão postal, carta aérea no estado ou carta aérea fora do estado. Esta prática era comum nas colônias alemãs gaúchas, de acordo com Roche (1969), devido à ausência de meios de comunicação nas colônias, recorria-se ao envio de correspondências pelos serviços postais para comunicações entre familiares e conhecidos mais distantes. Dessa forma, os alunos começavam a realizar operações de adição com números decimais sem um tratamento formal deste conteúdo, mas associada a uma prática sociocultural, inclusive com o uso de selos usados para registro de valores e escrita da linguagem monetária.

De acordo com Rambo (1994), a familiaridade com os diversos sistemas métricos significava um pré-requisito insubstituível para equipar as gerações de colonos. Neste sentido, as duas edições da Segunda Aritmética trazem uma proposta de estudo semelhante, partindo do metro em fita e de madeira, conforme se observa na Figura 6: 


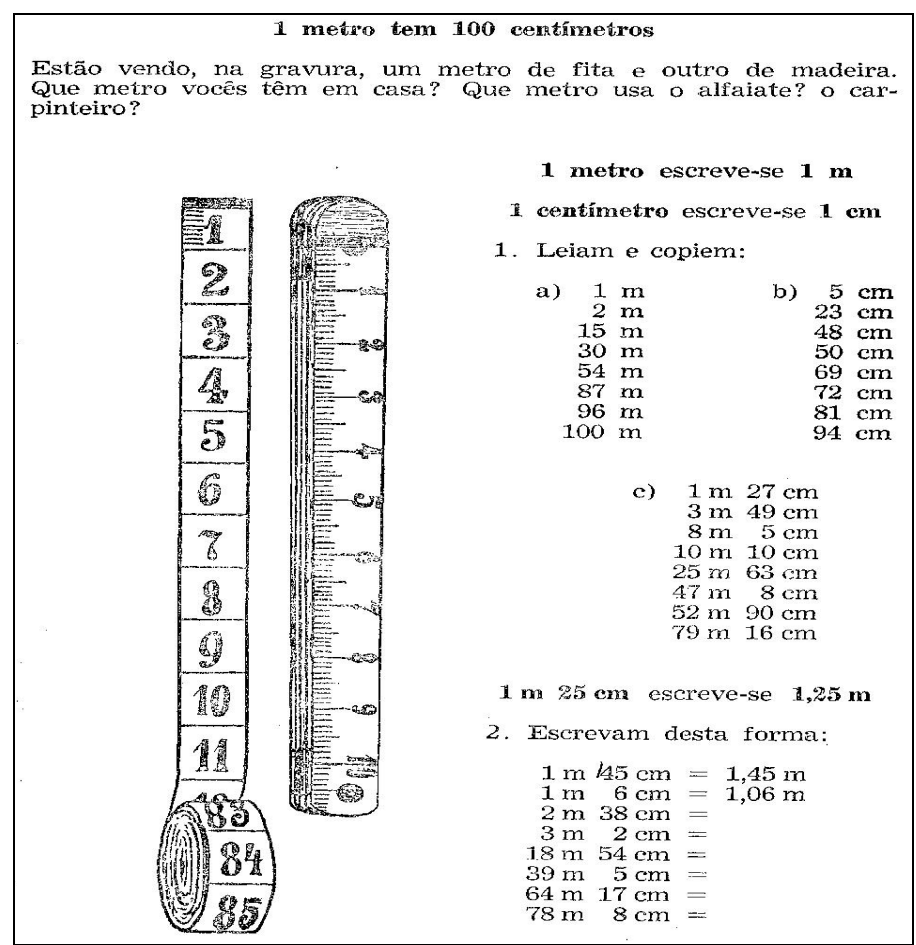

Figura 6 - Vamos lidar com o metro!

Fonte: Goerl, [194-b], p. 33.

No estudo da unidade de medida metro, o autor do livro sistematiza o conteúdo fazendo uso de ilustrações que representam o metro e associando-o com as profissões de alfaiate e de carpinteiro. A articulação entre a linguagem simbólica e os desenhos do metro, pode contribuir para os alunos associarem a unidade de medida de comprimento com o instrumento de medida e construírem relações entre metro e centímetros.

A Segunda Aritmética de Goerl [194-b] apresenta uma proposta de estudo para o sistema decimal, conforme fragmento na Figura 7:

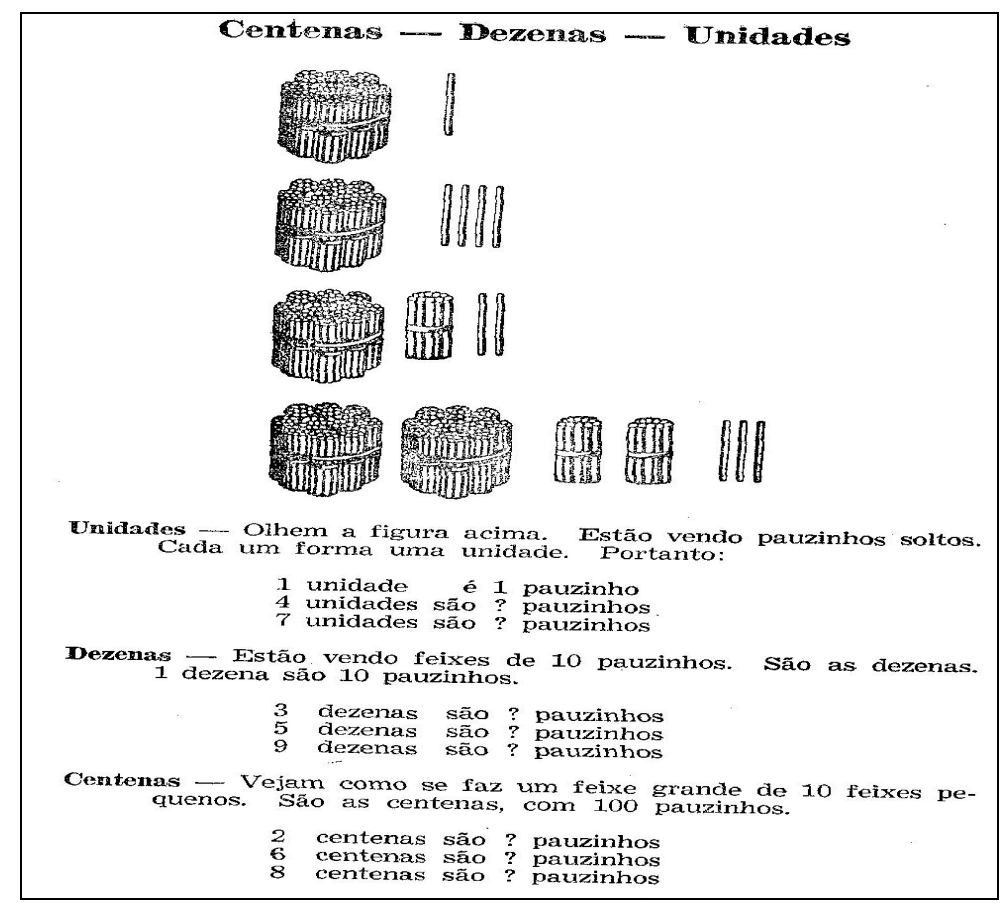

Figura 7 - Centenas, dezenas e unidades Fonte: Goerl, [194-b], p. 44. 
O uso de pauzinhos para estudo do sistema decimal já havia sido sugerido na Primeira Aritmética da série Ordem e Progresso. Goerl [194-b] propõe o estudo das centenas, dezenas e unidades, utilizando pauzinhos soltos para representar as unidades, feixes com 10 pauzinhos para representar as dezenas e 10 feixes com 10 pauzinhos cada para formar as centenas. Explora também as relações entre centenas, dezenas e unidades, isto é, 1 dezena é igual a 10 unidades e 1 centena é igual a 10 dezenas. Assim, usando um recurso visual o autor desenvolve a construção do sistema decimal, fazendo uma sistematização que engloba teoria e exemplos, seguida de atividades de aplicação que envolvem a composição e a decomposição dos números em centenas, dezenas e unidades.

O excerto da Segunda Aritmética apresentado na Figura 8 relaciona partes do corpo humano com a quantidade de dias dos meses do ano:

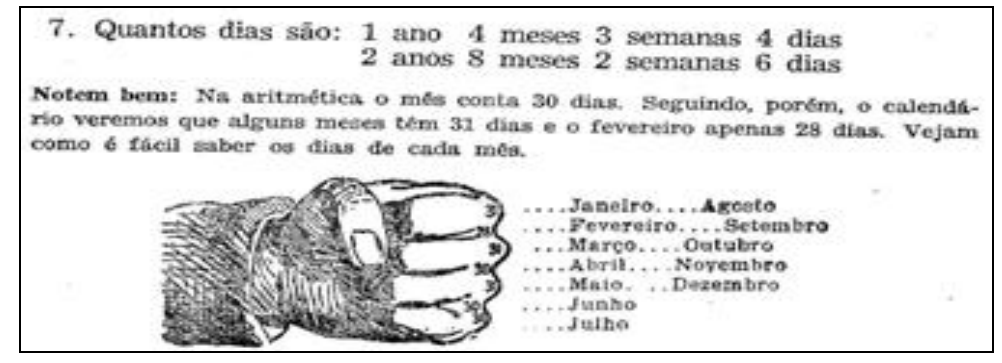

Figura 8 - A quantidade de dias dos meses do ano Fonte: Goerl, [194-b], p. 60.

O recorte do livro ilustrado na Figura 8 mostra quantos dias tem um mês utilizando os nós superiores dos dedos e os seus intervalos. A cada nó, intercalado com o intervalo com o próximo nó, é atribuído sequencialmente um mês, começando pelo mês de janeiro. O número de dias é dado da seguinte forma: se o mês está num nó do dedo, terá 31 dias; se o mês está num intervalo, então terá 30 dias, à exceção de fevereiro, que poderá ter 29 ou 28 dias, consoante seja ano bissexto ou não, respectivamente. Destaca-se que o livro traz uma informação incompleta, pois não faz referência ao mês de fevereiro com 29 dias em anos bissextos. Ressalta-se que esta associação e a informação incompleta sobre o número de dias do mês de fevereiro, também foram observadas na edição da Segunda Aritmética de 1948. Embora as informações estejam incompletas, acredita-se que a associação proposta nos livros pode auxiliar os alunos na memorização da quantidade de dias em cada mês do ano e está de acordo com orientações didáticas observadas no periódico Unsere Schule, quanto ao uso de partes do corpo humano para ensinar matemática.

Uma das primeiras propostas de estudo da Segunda Aritmética, editada em 1948, está relacionada com o sistema monetário. Para tanto, o livro apresenta cinco moedas, conforme se pode observar na Figura 9: 


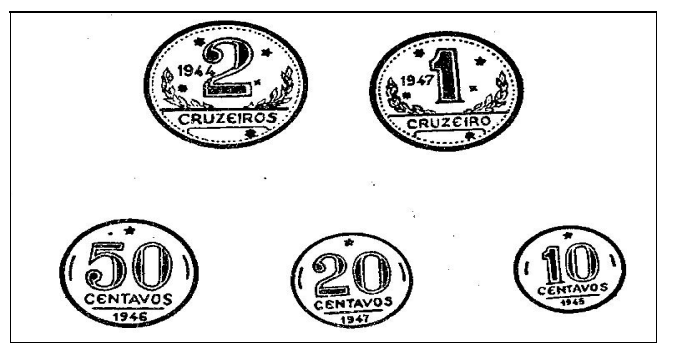

Figura 9 - As moedas

Fonte: Série Concórdia, 1948, p. 3.

A Figura 9 ilustra a representação das moedas de $\operatorname{Cr} \$ 0,10 ; \operatorname{Cr} \$ 0,20 ; \operatorname{Cr} \$ 0,50 ; \operatorname{Cr} \$$ 1,00 e Cr\$2,00. Em seguida, o livro apresenta exercícios envolvendo preços de mercadorias dispostos em tabelas. No Quadro 4 se apresenta uma tabela de preços, a partir da qual os alunos devem fazer 10 contas diferentes conforme os exemplos mostrados abaixo:

\begin{tabular}{|ll|} 
Quadro 4 - Preços & \\
\hline 1 caneta & $\mathrm{Cr} \$ 0,50$ \\
1 caderno & $\mathrm{Cr} \$ 0,40$ \\
1 lápis & $\mathrm{Cr} \$ 0,40$ \\
1 vidro de tinta & $\mathrm{Cr} \$ 0,30$ \\
1 caderneta & $\mathrm{Cr} \$ 0,20$ \\
1 pena & $\mathrm{Cr} \$ 0,10$ \\
\hline
\end{tabular}

Fonte: Série Concórdia, 1948, p. 4.

Exemplos extraídos da Segunda Aritmética (1948, p. 4):

$\begin{array}{llll}1 \text { caneta } & 0,50 & 2 \text { vidros de tinta } & \text { a } 0,30=0,60 \\ 1 \text { caderno } & 0,40 & 1 \text { caderneta } & \text { a } 0,20=0,20 \\ 1 \text { pena } & 0,10 & 2 \text { penas } & \text { a } 0,10=0,20\end{array}$

Cr\$1,00 Cr\$1,00

Observa-se tratar de uma proposta envolvendo operações de compra em que o aluno precisa ter noções do sistema monetário para constituir compras no valor de $\mathrm{Cr} \$ 1,00$, além de começar a familiarização dos alunos com os números decimais. A mesma edição traz outras tabelas com preços de produtos e serviços, propondo aos alunos a realização de cálculos a partir das informações contidas nas mesmas.

$\mathrm{Na}$ análise realizada, verificou-se que a Segunda Aritmética de 1948 incentiva a utilização de materiais concretos, conforme descrito no excerto a seguir: "O professor manda aos alunos medir diversos objetos existentes no colégio, confrontando as respectivas medidas (mesa, vidraças, bancos, mapas, cadernos, etc.)" (SÉRIE CONCÓRDIA, 1948, p. 13). A proposta do livro sugere ao aluno realizar a medida de objetos existentes na escola e depois comparar as respectivas medidas. Embora não esteja explícito, acredita-se que a atividade se realize com algum instrumento de medida, como por exemplo, a régua ou o metro.

$\mathrm{Na}$ Figura 10 se apresentam os pesos utilizados na balança decimal e na balança de pratos, ilustrados na Segunda Aritmética de 1948: 


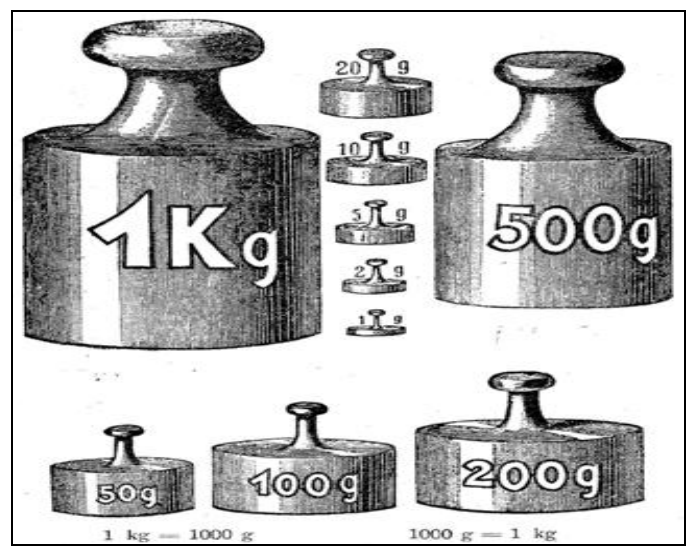

Figura 10 - Pesos

Fonte: Série Concórdia, 1948, p. 15.

Na Figura 10 se observam os pesos de 1 g, 2 g, 5 g, 10 g, 20 g, 50 g, 100 g, 200 g, 500 g e $1 \mathrm{~kg}$. Porém, na balança decimal ainda se utilizam pesos maiores, como $5 \mathrm{~kg}$. As representações mostradas nesta figura são exploradas em exercícios de composição de pesos ${ }^{9}$. Para compor 630 g, por exemplo, usam-se $500 \mathrm{~g}+100 \mathrm{~g}+20 \mathrm{~g}+10 \mathrm{~g}=630 \mathrm{~g}$. Esta ideia de composição era importante para compreensão do princípio de igualdade numa balança de pratos. Acredita-se que essa proposta do livro favoreceu a apropriação de conhecimentos matemáticos pelos alunos, contribuindo para o estudo das medidas de massa e a associação dessas medidas com situações vivenciadas em seu cotidiano.

Na Figura 11 se observa a balança de pratos, empregada para o estudo de unidades de medida de massa na edição da Segunda Aritmética de 1948:

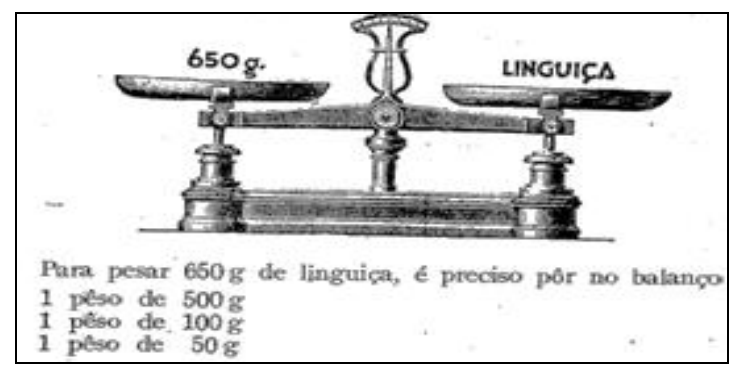

Figura 11 - Balança de pratos

Fonte: Série Concórdia, 1948, p. 16.

A balança de pratos era conhecida pelos alunos, pois fazia parte do cotidiano para obtenção das medidas de massa nas propriedades rurais e nas casas comerciais (vendas). A balança de pratos funciona com base no princípio de equilíbrio dos dois pratos, sendo utilizados na pesagem os pesos mostrados na Figura 10 deste artigo. No exemplo apresentado, para pesagem de $650 \mathrm{~g}$ de linguiça são necessários 1 peso de $500 \mathrm{~g}+1$ peso de $100 \mathrm{~g}+1$ peso de $50 \mathrm{~g}$. A proposta do livro explora a (de)composição de pesos a partir desta ideia.

\footnotetext{
${ }^{9}$ Para as unidades de medida de massa se usa o termo popular peso. Este erro conceitual da física é observado nas aritméticas analisadas, como por exemplo, na expressão relações entre as medidas de peso.
} 
A Figura 12 apresenta a ilustração de uma balança grande (decimal), encontrada na Segunda Aritmética de 1948:

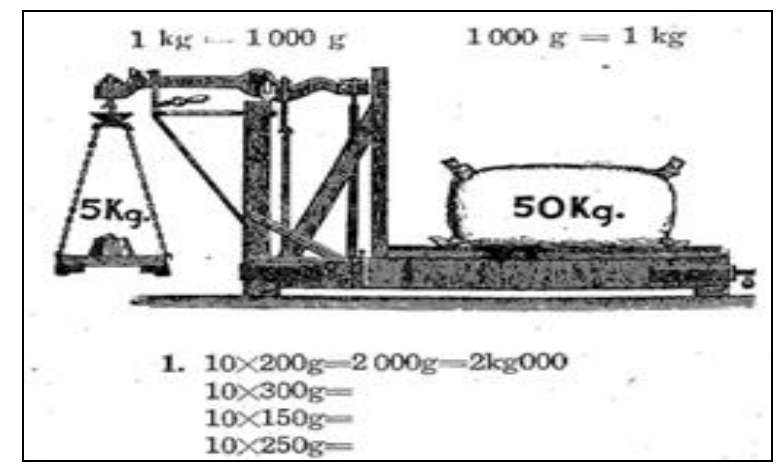

Figura 12 - Balança decimal

Fonte: Série Concórdia, 1948, p. 73.

As balanças decimais eram usadas para pesagem de produtos agrícolas, tanto nas propriedades rurais, quanto nas casas comerciais. Envolvem relações entre as unidades de medida de massa gramas (g) e quilogramas $(\mathrm{kg})$. Para pesagem de um saco com $50 \mathrm{~kg}$, por exemplo, era necessário colocar um peso de $5 \mathrm{~kg}$ no prato da balança decimal, pois $10 \mathrm{x} 5 \mathrm{~kg}$ $=50 \mathrm{~kg}$. A proposta pedagógica da Segunda Aritmética era familiarizar o aluno com o princípio de funcionamento de uma balança decimal, a qual multiplica por 10 o peso colocado no prato da balança. O exercício 1, mostrado na Figura 12, é proposto neste sentido e complementado com a transformação da unidade de medida de massa g para kg.

As principais unidades de estudo das duas edições da Terceira Aritmética são: frações decimais e sistema métrico; frações ordinárias; regra de três; porcentagem; porcentagem comercial; juros; razão e proporção; geometria prática. Estas aritméticas são caracterizadas por apresentarem propostas de estudo mais sistematizadas dos conhecimentos matemáticos.

O Quadro 5 apresenta um fragmento extraído da Terceira Arithmetica, com um termômetro clínico e a partir dele se exploram conhecimentos matemáticos.

Quadro 5 - O termômetro clínico

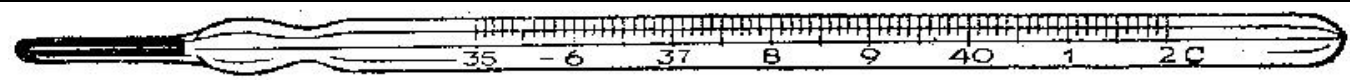

Este instrumento que serve para indicar a temperatura do homem se chama termômetro. Para determinar a temperatura exata, os graus do termômetro são divididos em décimos. $\mathrm{O}$ grau designa-se com um pequeno zero. P. ex. $15^{\circ}$. A temperatura do sangue do homem é de $36^{\circ}, 5$.

1) Ler a temperatura, indicada pelo termômetro.

2) Mostrar no termômetro $37^{\circ} ; 36^{\circ} ; 40^{\circ} ; 37^{\circ}, 5 ; 40^{\circ}, 2 ; 38^{\circ}, 9 ; 41^{\circ}, 7$.

3) A temperatura dum doente, de manhã é de $38^{\circ}$, à tarde de $39^{\circ}, 6$. Qual é a diferença?

4) Uma criança tem febre alta. $\mathrm{O}$ termômetro indica $40^{\circ}, 2$. Com a medicação baixou a 39'. Indicar a diferença.

Fonte: Série Concórdia, [193-], p. 2.

O Quadro 5 mostra a representação de um termômetro clínico e propõe atividades associadas a medidas de temperatura do corpo humano, explorando conhecimentos matemáticos que envolvem representação e operações com números decimais. Observa-se que 
a escrita das temperaturas com números decimais, nesta edição, é diferente da escrita empregada na Terceira Aritmética, também utilizada atualmente. Por exemplo:

$36^{\circ}, 5$ na Terceira Arithmetica da série Ordem e Progresso [193-];

36,5 na Terceira Aritmética da série Concórdia (1949).

As edições da Terceira Aritmética trazem a definição de metro relacionada com o meridiano terrestre, como se observa na Figura 13:

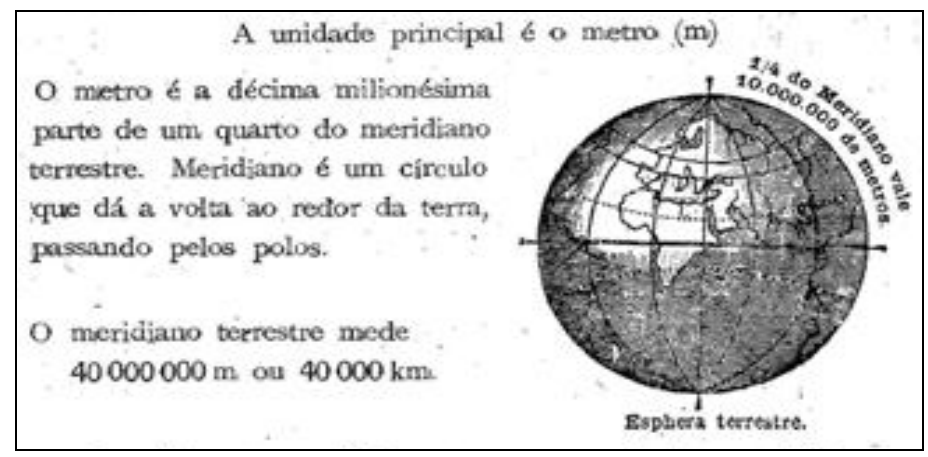

Figura 13 - O metro

Fonte: Série Concórdia, 1949, p. 2.

O excerto, apresentado na Figura 13, mostra que a medida de comprimento metro é definida a partir do meridiano terrestre, relacionando-se esta ideia com a forma esférica da terra. Para se encontrar um metro é preciso fracionar os $90^{\circ}$ correspondentes ao quadrante de um meridiano terrestre em 10000000 partes iguais e uma delas terá o mesmo comprimento de um metro. Devido à necessidade de mais precisão, em 1983, na $17^{\mathrm{a}}$ Conferência Geral de Pesos e Medidas, realizada em Paris, o metro passou a ser definido a partir da velocidade de propagação eletromagnética. Segundo o Instituto Nacional de Metrologia - INMETRO, o metro é definido atualmente como "o comprimento do trajeto percorrido pela luz no vácuo durante um intervalo de tempo de 1/299792458 de segundo”. A estratégia de contextualização da definição de metro com a geografia (meridiano terrestre) serve de motivação para o estudo de outras medidas de comprimento, como quilômetro $(\mathrm{km})$, hectômetro $(\mathrm{hm})$, decâmetro (dam), milímetro (mm), centímetro (cm) e decímetro (dm).

Na Figura 14 se observa uma nota de compra de mercadorias, encontrada numa edição da Terceira Aritmética, envolvendo operações com números decimais:

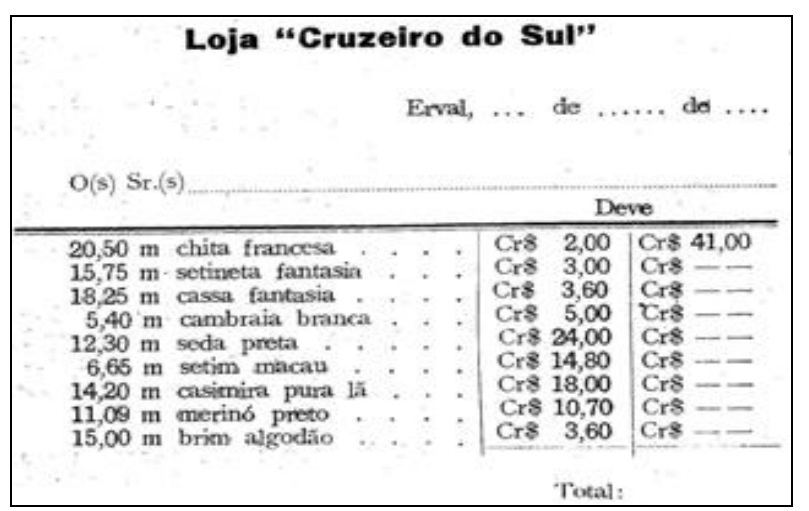

Figura 14 - Nota de compra de mercadorias Fonte: Série Concórdia, 1949, p. 78. 
O excerto, mostrado na Figura 14, propõe ao aluno completar uma nota de compra de mercadorias, explorando-se as operações de multiplicação e adição com números decimais. Essas atividades envolvendo as notas de compra, também observadas nas edições da Segunda Aritmética, estão relacionadas com práticas sociais desenvolvidas no contexto das comunidades em que as escolas paroquiais luteranas gaúchas estavam inseridas.

A análise das aritméticas da série Ordem e Progresso e da série Concórdia, direcionadas para as escolas paroquiais luteranas gaúchas, no século passado, permitiu um adentramento na cultura escolar num lugar e num tempo determinados, identificando-se recursos didáticos nesse contexto, conforme a discussão realizada e considerações finais apresentadas na sequência deste artigo.

\section{Considerações finais}

Partindo do referencial teórico-metodológico da história cultural se investigaram os recursos didáticos observados nas aritméticas da série Ordem e Progresso e da série Concórdia, editadas pela IELB, por meio da Casa Publicadora Concórdia, na primeira metade do século XX, para suas escolas no RS. Neste contexto missionário e de formação geral, a Igreja Luterana editou livros didáticos de acordo com seus princípios morais e educacionais, adaptando-se ao processo de nacionalização do ensino.

$\mathrm{Na}$ análise realizada se verificou que as aritméticas trazem ilustrações para o desenvolvimento de conhecimentos matemáticos relacionados com a construção intuitiva do conceito de número e o estudo das frações ordinárias; unidades de medida de comprimento, massa, tempo e temperatura; sistema monetário e documentos fiscais (tabelas com preços e notas de compra e venda de mercadorias). Acredita-se que a estratégia dos autores de utilizarem as ilustrações tenha favorecido o processo de ensino e aprendizagem da matemática, pois as mesmas faziam parte de diferentes contextos da realidade dos alunos das escolas paroquiais luteranas gaúchas do século passado.

Os autores das aritméticas da série Ordem e Progresso e da série Concórdia incentivam a utilização de materiais concretos, como o ábaco e pauzinhos de madeira no estudo do sistema decimal e das quatro operações elementares com números naturais até 100; fitas de papel, frutas, grãos de milho e livros no estudo das frações ordinárias; partes do corpo humano para fixação da quantidade de dias dos meses do ano; o almanaque para estudo de unidades de medida de tempo; selos para o estudo dos números decimais. Também se observam propostas de uso da régua para realização de medidas de comprimento de espaços e objetos do contexto dos alunos. 
Destaca-se que as aritméticas analisadas não fazem referência ao uso de jogos para o ensino da matemática. A Primeira Aritmética da série Concórdia e as edições da Segunda e da Terceira Aritmética ainda exploram a resolução de problemas do contexto dos alunos e trazem curiosidades e desafios matemáticos, porém, em função da delimitação de espaço, a análise destes recursos didáticos integrará outras publicações.

Ressalta-se que o ensino da matemática nas escolas paroquiais luteranas gaúchas do século passado foi caracterizado pelo desenvolvimento de habilidades para o cálculo mental e escrito, de forma prática e contextualizado, para que os futuros colonos fizessem a correta administração do orçamento familiar e o gerenciamento da sua propriedade rural. Mesmo que as aritméticas da série Ordem e Progresso e da série Concórdia tenham sido editadas num período marcado pelo movimento da Escola Nova no Brasil e que, algumas propostas dos autores estejam alicerçadas no método de ensino intuitivo, as mesmas ainda refletem a tradição pedagógica da memorização.

\section{Referências}

ARENDT, I. C. Representações de Germanidade, Escola e Professor no Allgemeine Lehrerzeitung für Rio Grande do Sul [Jornal Geral para o Professor no Rio Grande do Sul]. Tese de doutorado em História - Universidade do Vale do Rio dos Sinos, São Leopoldo, 2005.

CHARTIER, R. A História Cultural: entre práticas e representações. Lisboa: Difel, 1990.

CHERVEL, A. História das disciplinas escolares - reflexões sobre um campo de pesquisa. Teoria \& Educação, n. 2, p. 177-229, 1990.

GOERL, O. A. Série Concórdia: Primeira Aritmética. Porto Alegre: Casa Publicadora Concórdia, [194-a].

GOERL, O. Série Concórdia: Segunda Aritmética. Porto Alegre: Casa Publicadora Concórdia, [194-b].

JULIA, D. A cultura escolar como objeto histórico. Revista Brasileira de História da Educação, n. 1, p. 9-43, 2001.

KREUTZ, L. Livros escolares e imprensa educacional periódica dos imigrantes alemães no Rio Grande do Sul, Brasil 1870-1939. Revista Educação em Questão, v. 31, n. 17, p. 24-52, 2008.

KREUTZ, L. Material didático e currículo na escola teuto-brasileira. São Leopoldo: Ed. UNISINOS, 1994.

KREUTZ, L. O professor paroquial: magistério e imigração alemã. Porto Alegre: Ed. da UFRGS; Caxias do Sul: EDUCS, 1991. 
KREUTZ, L.; ARENDT, I. C. (Org.). Livros escolares das escolas de imigração alemã no Brasil (1832-1940). Acervo documental e de pesquisa, Biblioteca UNISINOS. São Leopoldo, 2007. 3 CD-ROM.

KUHN, M. C. O ensino da matemática nas escolas evangélicas luteranas do Rio Grande do Sul durante a primeira metade do século XX. Tese de doutorado em Ensino de Ciências e Matemática - Universidade Luterana do Brasil, Canoas, 2015.

LEMKE, M. D. Os princípios da educação cristã luterana e a gestão de escolas confessionárias no contexto das ideias pedagógicas no sul do Brasil (1824 - 1997). Canoas: Ed. ULBRA, 2001.

LINDEMANN, J. C. W. Amerikanisch-Lutherische Schul-Praxis. 2. ed. Sant Louis: Lutherischer Concordia - Verlag, 1888.

MAURO, S. Uma história da matemática escolar desenvolvida por comunidades de origem alemã no Rio Grande do Sul no final do século XIX e início do século XX. Tese de doutorado em Educação Matemática - Universidade Estadual Paulista, Rio Claro, 2005.

NUNES, C. Historiografia comparada da escola nova: algumas questões. Revista da Faculdade de Educação, v. 24, n. 1, p. 105-125, 1998.

RAMBO, A. B. A escola comunitária teuto-brasileira católica. São Leopoldo: Ed. UNISINOS, 1994.

RAMBO, A. B. A escola comunitária teuto-brasileira católica: a associação de professores e a escola normal. São Leopoldo: Ed. UNISINOS, 1996.

ROCHE, J. A Colonização Alemã e o Rio Grande do Sul. Porto Alegre: Editora Globo, 1969. v. 1 e v. 2.

ROCKENBACK, S. A.; FLORES, H. A. H. Imigração alemã: 180 anos - história e cultura. Porto Alegre: CORAG, 2004.

SÉRIE Concórdia: Segunda Aritmética. Porto Alegre: Casa Publicadora Concórdia, 1948.

SÉRIE Concórdia: Terceira Aritmética. Porto Alegre: Casa Publicadora Concórdia, 1949.

SÉRIE Ordem e Progresso: Terceira Arithmetica. Porto Alegre: Casa Publicadora Concórdia, [193-].

SILVA, C. M. S. A aritmética de Matthäus Grimm no boletim informativo da associação de professores católicos da imigração alemã no Rio Grande do Sul. In: SEMINÁRIO TEMÁTICO - SABERES ELEMENTARES MATEMÁTICOS DO ENSINO PRIMÁRIO (1890 - 1970): O QUE DIZEM AS REVISTAS PEDAGÓGICAS? (1890 - 1970), 12., 2015, Curitiba. Anais... Curitiba: PUCPR, 2015. p. 23-38.

SILVA, C. M. S. Friedrich Bieri e a matemática para o ensino primário nas escolas teutobrasileiras. In: SEMINÁRIO TEMÁTICO - A CONSTITUIÇÃ̃O DOS SABERES ELEMENTARES MATEMÁTICOS: A ARITMÉTICA, A GEOMETRIA E O DESENHO 
NO CURSO PRIMÁRIO EM PERSPECTIVA HISTÓRICO-COMPARATIVA, 1890-1970, 11., 2014, Florianópolis. Anais... Florianópolis: UFSC, 2014. p. 1-22.

STRELOW, F. Série Ordem e Progresso: Primeira Aritmética. Porto Alegre: Casa Publicadora Concórdia, [193-].

UNSERE SCHULE. Porto Alegre: Casa Publicadora Concórdia, 1933-1935.

VALDEMARIN, V. T. Estudando as lições de coisas: análise dos fundamentos filosóficos do Método de Ensino Intuitivo. Campinas: Autores Associados, 2004.

VALENTE, W. R. História da Educação Matemática: interrogações metodológicas. REVEMAT - Revista Eletrônica de Educação Matemática, v. 2.2, p. 28-49, 2007.

VALENTE, W. R.; PINHEIRO, N. V. L. Chega de decorar a tabuada! - As cartas de Parker e a árvore do cálculo na ruptura de uma tradição. Educação Matemática em Revista - RS, Canoas, v. 1, n. 16, p. 22-37, 2015.

WANDERER, F. Escola e Matemática Escolar: mecanismos de regulação sobre sujeitos escolares de uma localidade rural de colonização alemã no Rio Grande do Sul. Tese de doutorado em Educação - Universidade do Vale do Rio dos Sinos, São Leopoldo, 2007.

WARTH, C. H. Crônicas da Igreja: Fatos Históricos da Igreja Evangélica Luterana do Brasil (1900 a 1974). Porto Alegre: Concórdia, 1979.

WEIDUSCHADT, P. A revista “O Pequeno Luterano" e a formação educativa religiosa luterana no contexto pomerano em Pelotas - RS (1931-1966). Tese de doutorado em Educação - Universidade do Vale do Rio dos Sinos, São Leopoldo, 2012.

WEIDUSCHADT, P. O Sínodo de Missouri e a educação pomerana em Pelotas e São Lourenço do Sul nas primeiras décadas do século XX: identidade e cultura escolar. Dissertação de mestrado em Educação - Universidade Federal de Pelotas, Pelotas, 2007.

WILLEMS, E. A aculturação dos alemães no Brasil: estudo antropológico dos imigrantes alemães e seus descendentes no Brasil. 2. ed. São Paulo: Editora Nacional, 1980.

\section{SOBRE OS AUTORES}

MALCUS CASSIANO KUHN. Possui Graduação em Ciências - Licenciatura Plena em Matemática - pela Universidade Luterana do Brasil (2003). É Especialista em Pedagogia Gestora: Orientação, Supervisão e Administração Escolar pela Faculdade de Ciências Sociais (2006), Mestre em Ensino de Ciências e Matemática pela Universidade Luterana do Brasil (2008) e Doutor em Ensino de Ciências e Matemática pela Universidade Luterana do Brasil (2015). Atualmente é Pós-Doutorando no Programa de Pós-Graduação em Ensino de Ciências e Matemática da Universidade Luterana do Brasil e Professor do Ensino Básico, Técnico e Tecnológico no Instituto Federal de Educação, Ciência e Tecnologia Sul-rio-grandense IFSul Câmpus Lajeado/RS. Também é membro do Grupo de Estudos e Pesquisas em História da Educação Matemática e Interculturalidade - GEPHEMI.

ARNO BAYER. Possui graduação em Matemática pela Faculdade Porto Alegrense (1974). É Doutor em Educação pela Universidad Pontificia de Salamanca (1997). Atualmente é 
professor titular da Universidade Luterana do Brasil e professor orientador do Programa de Pós-Graduação em Ensino de Ciências e Matemática (PPGECIM - ULBRA) no Mestrado e Doutorado. Avaliador de Curso de Graduação e Avaliador Institucional do Sistema Nacional de Avaliação da Educação Superior. Também é Coordenador do Grupo de Estudos e Pesquisas em História da Educação Matemática e Interculturalidade - GEPHEMI.

Recebido: 04 de agosto de 2016.

Revisado: 11 de outubro de 2016.

Aceito: 12 de dezembro de 2016. 